\title{
O uso de softwares educativos no processo de ensino e aprendizagem de alunos com deficiência intelectual
}

\section{Carolina da Costa Carvalho}

Faculdade Anhanguera de Bauru (FAB), Bauru - SP - Brasil. Graduada em Pedagogia. E-mail: carolinacarvalho2804@hotmail.com

\section{José Anderson Santos Cruz}

Faculdade Anhanguera de Bauru (FAB), Bauru - SP - Brasil. Docente da graduação e pós-graduação. Doutorando em Educação Escolar pela Faculdade de Ciências e Letras, FCLAr/Unesp. Prof. Orientador e colaborador com a pesquisa. OrcID: <https://orcid.org/0000-0001-5223-8078>. Lattes: $<$ http://lattes.cnpq.br/2419735299778580>. E-mail:

joseandersonsantoscruz@gmail.com

\section{Arielly Kizzy Cunha}

Universidade Estadual Paulista (UNESP), Bauru - SP - Brasil. Doutoranda do Programa de Pós Graduação em Mídia e Tecnologia da FAAC Unesp Bauru. Profa. Coorientadora e colaboradora com a pesquisa. Email: ariellykizzy@gmail.com 


\section{Resumo}

Este trabalho ${ }^{1}$ de conclusão de curso tem como propósito apresentar uma breve descrição e compreensão das particularidades da pessoa com deficiência intelectual no que diz respeito ao quadro principal de prejuízo cognitivo (as funções intelectuais) e adaptativo (emocional, funções sociais, e práticas), para, então, definir as possibilidades da prática pedagógica com o uso de um software educativo. Foram pesquisados conceitos, tipos e classificações sobre alguns softwares educativos livres, buscando melhores formas de aplicá-los nas pessoas com deficiência Intelectual inseridos em escola regular. Dessa forma, o tipo da pesquisa realizada foi qualitativo, tendo por base a pesquisa bibliográfica, sendo estes os meios pelos quais foi obtida a fundamentação teórica. No entanto, desenvolver um software educativo voltado para pessoas com deficiência intelectual com todos os requisitos pedagógicos específicos, é um trabalho árduo, haja vista que para isso há a necessidade de seguir uma série de etapas para que o produto possa atingir inteiramente seu objetivo. Este resultado garante um processual caminho, no qual se busca por meio dos comportamentos adaptativos, avaliações e métodos de ensino, capacitar essas pessoas e dar um norte ao educador no processo de conhecimento do aluno e de suas potencialidades.

Palavras-chave: Software educativo. Deficiência intelectual. Processo de aprendizagem.

\section{Abstract}

This work aims to present a brief description and understanding of the particularities of the person with intellectual disability in relation to the main frame of cognitive (intellectual functions) and adaptive impairment (emotional, social functions, and practices), to define the possibilities of pedagogical practice with the use of an educational software. We researched concepts, types and classifications about some free educational software, seeking better ways of applying them to people with intellectual disabilities inserted in regular school. In this way, the type of research carried out was qualitative, based on bibliographical research, and these were the means by which the

\footnotetext{
${ }^{1}$ Este texto originou-se a partir do Trabalho de Conclusão de Curso (2019), da graduação plena em Pedagogia na Faculdade Anhanguera de Bauru.
} 
theoretical basis was obtained. However, developing educational software for people with intellectual disabilities with all the specific pedagogical requirements is hard work, because in order to do this there is a need to follow a series of steps so that the product can fully reach its goal. This result guarantees a procedural way, in which one searches through adaptive behaviors, evaluations and teaching methods, to train these people and to give a north to the educator in the student's knowledge process and its potentialities.

Keywords: Educational software. Intellectual disability. Learning process.

\section{Introdução}

A pessoa que apresenta deficiência intelectual em sua grande maioria é considerada como "incapaz" de aprender, atitude vista por muitas pessoas da sociedade, e por esse motivo deixam de ofertar oportunidades.

Por isso, há necessidade de um estudo que discuta o uso de softwares educativos na construção do conhecimento de pessoas com deficiência intelectual, bem como as contribuições para a desconstrução da lógica vigente de que toda pessoa com deficiência tem dificuldades que dificultam o processo de aprendizagem, ou seja, não se acredita nas possibilidades dessa pessoa.

A finalidade desse tipo de software é a comunicação, a qual se torna uma ferramenta a mais dentro da comunicação alternativa para pessoas com deficiência intelectual, cuja expectativa é que o aluno consiga alcançar aprendizagem significativa dentro de suas potencialidades, a chamada alfabetização social. Assim aprender hoje para que amanhã ele possa se comunicar com o mundo.

Partindo desse princípio, existe uma problemática a ser estudada e discutida, sobre qual a real contribuição do uso de softwares educativos no processo de ensino e aprendizagem de alunos com deficiência intelectual? $\mathrm{O}$ objetivo geral desta pesquisa é compreender e identificar, além das dificuldades e limitações, as potencialidades e o progresso dos alunos com deficiência intelectual, tendo como objetivos específicos: conceituar o que é deficiência intelectual, pontuar a educação especial, seus princípios e conceitos e destacar os tipos e classificações de software educativo. 
A pesquisa consiste em um levantamento bibliográfico com abordagem qualitativa descritiva, sendo que para isso será utilizado livros de bibliotecas particulares e públicas, revistas, jornais, artigos e endereços eletrônicos que tiveram suas datas de publicações entre o período de 1980 e 2018. A pesquisa bibliográfica, de acordo com Gil (1996, p. 19), o qual define como “[...] um procedimento racional e sistemático que tem como objetivo proporcionar respostas aos problemas que são propostos

Nesse contexto, o conceito de software educativo, tipos e classificações dos softwares no ambiente educativo e pesquisa de software educativos livres, interfaces e suas interatividades levando em conta suas especificidades.

Para concluir, um ambiente pedagógico, quando informatizado, propicia que o educando com deficiência intelectual tenha um melhor desenvolvimento cognitivo, se houver o intermédio de um (a) educador (a) especialista, com o objetivo de alcançar o desenvolvimento pleno desta pessoa como um ser social e histórico, olhando para essa pessoa não com um ser limitado e inferior, mas como uma pessoa que aprende de forma diferente dos padrões e das normas especificadas pela sociedade dos ditos "normais".

\section{Fundamentação Teórica}

\section{CONCEITO DE DEFICIÊNCIA INTELECTUAL}

O propósito desta escrita é dar uma composição a quem se destina o software que está sendo estudado.

Segundo a Associação Americana sobre Deficiência Intelectual do Desenvolvimento (AAIDD), a deficiência intelectual (DI) é caracterizada pelo déficit de inteligência expressivamente inferior à média, tendo associadas limitações a duas ou mais áreas de habilidades adaptativas (autocuidado, atividades da vida diária, comunicação, adaptação social, segurança, saúde, determinação, trabalho e lazer).

Ferreira (1997) apresenta as características da deficiência intelectual como educáveis, ou seja, com menor comprometimento. São as seguintes: vocabulário limitado, aprendizagem muito lenta, dificuldades de adaptação pessoal e social, limitações de aprendizagem espontânea, atenção dirigida limitada, comportamento 
apresentando agressividade, autodesvalorização, tendência à frustração, teimosia, automatismo, falta de censura, educabilidade.

Ainda de acordo com Ferreira (1997), nessa definição, surgem conceitos fundamentais: desenvolvimento, aprendizagem e ajustamento social, iniciando, de certa forma, uma nova era quanto às expectativas, o que consequentemente, acentua o enfoque educacional das definições de deficiência intelectual.

A inteligência foi por um longo tempo avaliado por intermédio do quociente de inteligência (Q. I.). Contudo, hoje, o que se leva em consideração para diagnóstico da deficiência intelectual é por meio dos comportamentos adaptativos.

De acordo com Déa e Duarte (2009) alguns indivíduos apresentam escores baixos no teste de quociente de inteligência e são altamente sociáveis e eficientes em suas atividades de vida diária.

Os indivíduos com a chamada inteligência normal têm quociente de inteligência entre 70 a 130, já as pessoas que apresentam quociente de inteligência abaixo são consideradas deficientes intelectuais.

Existem diversas correntes para definir o nível da deficiência mental, porém para classificar o grau de deficiência utilizam-se as práticas psicométricas que medem o Q. I.

A pessoa que tem deficiência intelectual evidencia diferentes condições no que diz respeito ao ensino aprendizagem e vários outros fatores estão presentes, atrapalhando a sua vida escolar, porém, não demonstra uma incapacidade generalizada, possuindo diversas habilidades e capacidades que possibilitam o seu desenvolvimento global.

Não tem como definir a deficiência mental, por um único saber, pois ela não se esgota na sua condição intelectual e/ou orgânica. Portanto ela é um grande ponto de interrogação, passando a ser objeto de investigação de várias áreas da ciência (MANTOAN; BATISTA, 2007, p. 15).

É importante destacar que existem inúmeras pessoas que rotulam o termo deficiente, passando a olhar a pessoa como um ser deficiente e não como uma pessoa que possui deficiência. 
No Brasil, a partir da Constituição Federal de 1988, foi dado ênfase às pessoas com deficiências, em seu artigo 208, inciso III, afirmando ser dever do Estado "o atendimento educacional especializado aos portadores de deficiência”.

Aprovada pela Organização das Nações Unidas (ONU) em 2006, a convenção sobre os Direitos das Pessoas com Deficiência, define em seu artigo $1^{\circ}$ que:

\begin{abstract}
Pessoas com deficiências são aquelas que têm impedimento de natureza física, intelectual ou sensorial, os quais em interação com diversas barreiras podem obstruir sua participação plena e efetiva na sociedade com as demais pessoas (BRASIL, 2009).
\end{abstract}

De acordo com Fonseca (1987), na década de 80, uma das questões de mais complicadas da vida de um deficiente intelectual é a entrada na escola ou empresa, pois nesse momento os laços fortes entre família e comodidades se desfazem.

A proposta dentro desta nova reflexão é conhecer mais a deficiência e assim contribuir para proporcionar uma melhor oportunidade educacional para as pessoas com deficiência intelectual.

Mantoan (2001) descreve que o aluno deficiente intelectual é capaz de se autoconstruir cognitiva, afetiva, e socialmente de acordo com a sua capacidade. Sua aprendizagem é formada por intermédio de informações, valores e atitudes interiorizados a partir de modelagens comportamentais e condicionamentos.

Ainda de acordo com o Mantoan (2001), se faz necessário acrescentar que as avaliações realizadas podem ser úteis não apenas a deficiência intelectual, mas em outras como: deficiente auditivo, deficiente físico, deficiências múltiplas que validam o esforço em tentar melhorar a estrutura educacional encontrada nos dias atuais.

A colaboração pedagógica para que se realize algo inovador dentro dos parâmetros educacionais deve ser agora; criar um instrumento avaliativo utilizando técnicas menos complexas, conhecendo sua natureza, pode auxiliar muito aos professores dentro de instituições.

Déa e Duarte (2009) afirmam que sem nenhuma intervenção, seja dos pais ou educadores, as dificuldades persistem até mais tarde na vida das pessoas com deficiência intelectual e, quando mais cedo realizar o diagnóstico e a intervenção, melhor será seu desenvolvimento. 


\section{COMPORTAMENTOS ADAPTATIVOS}

De acordo com a (A.A.M.R) American Association on Mental Retardation (2006) o comportamento adaptativo é o conjunto das habilidades conceituais, sociais e práticas que são aprendidas no cotidiano de suas vidas diárias, as limitações no comportamento adaptativo afetam tanto na vida diária como em sua vivência dentro de ambientes, família e sociedade.

O comportamento adaptativo é descrito como um instrumento de avaliação de deficiência intelectual, utilizado por professores para avaliar o grau de dificuldade e desempenho dos alunos, por meio de atividades adaptadas e pode ser realizado por profissionais de saúde e educação.

Lefrançóis (2008) afirma que a maior área de desenvolvimento do deficiente intelectual é o domínio comportamental, os comportamentos são aprendidos com mais facilidade quando reforçados, outros com muita dificuldade.

Ainda segundo o Lefrançóis (2008), pessoa com deficiência intelectual é a deficiência ou grau com o qual o indivíduo preenche as normas de independência pessoal e responsabilidade que são esperados por idade e por grupo social.

Utilizando a estratégia dos comportamentos adaptativos, é possível realizar diversas formas de lidar com a deficiência intelectual em relação a sua aprendizagem.

As estratégias do comportamento devem ligar-se aos conteúdos sugeridos, mostrando possibilidades, por meio de experiências, para assim, relacionar o desenvolvimento intelectual e motor do indivíduo, uma vez que para haver uma mudança na qualidade do movimento que está sendo ensinado, é necessário, primeiro, uma ação adaptativa, que representa o ponto de partida para a ação do indivíduo sobre os objetivos do conhecimento. Essas envolvem estruturas cognitivas solicitadas, inquiridas durante o processo de desenvolvimento da ação adaptativa.

Alunos que exibem problema de concentração necessitam de um ambiente organizado, uma rotina, regras e atividades lógicas. Como a sala de aula tem muitas informações, é mais complicado manter o foco, por isso, o ideal é que as aulas sejam inicializadas, de forma prática e instrumentalizadas (RODRIGUES, 2009).

O computador é uma grande ferramenta usada por ser um excelente atrativo de manuseio, pois oferecem alguns recursos como animação, som, efeitos especiais, que em 
conjunto com um software educativo adequado com a faixa etária do aluno, provoca o interesse do mesmo nas atividades educacionais sugeridas.

Segundo a afirmativa de Santarosa (1996, p. 15), o computador é:

Uma 'prótese física' pelo conjunto de dispositivos e procedimentos que visam o desempenho de funções que o corpo não pode ou tem dificuldades de executar devido à deficiência [...]. Uma "prótese mental" através dos processos de intervenção sobre portadores de necessidades especiais visando o seu desenvolvimento cognitivo, sócio afetivo e de comunicação, utilizando os recursos da Informática [...].

Dessa forma, o professor tem um papel muito importante, não só na escolha do software a ser utilizado, mas também na elaboração de um plano de ensino, tendo em vista à interação deste com o computador, observando se o mesmo apresenta alguma dificuldade, facilitando assim a reelaboração de atividades que beneficie o processo de aprendizagem.

Para Werner (2008), é fundamental que o professor aprenda a escolhê-los, tendo em vista os objetivos a serem atingidos, pois o software educativo deve de estimular o raciocínio e motivar que o usuário interaja com o programa.

A mediação do professor junto à necessidade do aluno é muito importante, pois oferece muitas possibilidades interativas na qual é considerada uma extraordinária ferramenta de comunicação para o educando com vistas ao processo de aprendizagem.

\section{CONTRIBUIÇÕES DA TECNOLOGIA PARA UMA MELHOR DIDÁTICA DE ENSINO PARA ALUNOS COM DEFICIÊNCIA INTELECTUAL}

Para Cardozo (2011), aprender é um processo complexo e dinâmico que resulta na mudança de comportamento após determinada experiência, estando relacionadas aos fatores comportamentais, afetivos, psicológicos, sociais e orgânicos de cada indivíduo. São várias as possíveis causas que podem levar um aluno a apresentar dificuldades e falhas que prejudicam esse processo. 
O professor deve ter pleno discernimento e sabedoria sobre o conteúdo, assim, os alunos analisam os conteúdos de forma clara, com o foco em sua experiência de vida, retendo o conteúdo de forma clara em sua mente.

De acordo com Omete (1994), diferentemente da tendência atual da Educação Especial, em que se busca primordialmente aumentar a capacidade pessoal, deve-se também procurar meios de alterar a demanda das atividades em relação à qual a pessoa é deficiente. Não significa reduzir os níveis de exigência, mas adequar a atividade, em parte, às condições de realização da pessoa.

Mesmo apresentando dificuldades, as pessoas com deficiência intelectual estão expostas às tecnologias avançadas e algumas já se utilizam delas, mesmo que ainda tímidos, "quebrando" a resistência de explorar o mundo digital.

As inovações tecnológicas da informação e comunicação prometem causar uma grande transformação da vida em sociedade ao admitir que todos falem e se façam ouvir, sendo isso a condição chave para a idealização de uma sociedade igualitária e participativa a todos as pessoas. Portanto, a necessidade de permitir a todos sem exclusão o acesso ao mundo virtual e digital (SANTAROSA, 1996, p. 87)

Com a chegada dessa nova realidade nas escolas que contam com sala de recurso, há necessidade de se ter um professor especialista na área de educação especial que será o responsável por este ambiente, gerenciando e selecionando os recursos adequados, pois ele não será um mero transmissor de informações, mas sim o facilitador da construção do conhecimento pelo educando.

De acordo com Gouvea (1999), o professor é uma peça muito importante, pois ele precisa adquirir conhecimento dessa tecnologia para poder introduzi-la na sala de aula, do mesmo jeito que um dia ele introduziu seu primeiro livro em uma escola e tendo que trabalhar de maneira diferente com o conhecimento - sem deixar de lado as outras tecnologias de comunicação.

Segundo Kenski (2007), os recursos tecnológicos oferecem oportunidades que proporcionam o enriquecimento do aprendizado e são apresentados como um recurso de pensar e ver o mundo, valendo-se de uma nova percepção, por meio da imagem eletrônica, que abrange um pensamento dinâmico, em que velocidade, tempo, e 
movimento são os novos aliados no processo de ensino aprendizagem e permite aos professores e alunos desenvolverem seus pensamentos, de forma crítica e lógica, sua capacidade de observação, sua criatividade por intermédio do despertar da curiosidade e seu convívio com equipes de trabalho na criação de projetos.

\section{POLÍTICA NACIONAL E EDUCAÇÃO ESPECIAL}

No Brasil, a partir da Constituição Federal de 1988, foi dado ênfase às pessoas com deficiências, em seu artigo 208, inciso III, afirmando ser dever do Estado "o atendimento educacional especializado aos portadores de deficiência”.

É importante destacar que existem inúmeras pessoas que rotulam o termo deficiente, passando a olhar a pessoa como um ser deficiente e não como uma pessoa que possui deficiência.

Aprovada pela Organização das Nações Unidas (ONU) em 2006, a convenção sobre os Direitos das Pessoas com Deficiência, define em seu artigo $1^{\circ}$ que:

\footnotetext{
Pessoas com deficiências são aquelas que têm impedimento de natureza física, intelectual ou sensorial, os quais em interação com diversas barreiras podem obstruir sua participação plena e efetiva na sociedade com as demais pessoas (BRASIL, 2009).
}

Assim, torna-se claro que quando usa a expressão pessoa deficiente, refere a pessoas que apresentam alguma deficiência, ressaltando que não se trata de uma categoria, mas de um ser humano que possui limitações e capacidades.

Em 1990 foi criada da Secretaria Nacional de Educação Básica (SENEB), a qual assumiu a responsabilidade de implementar a política da educação especial, entendendo que, por ser educação especial uma modalidade do Sistema Educacional Brasileiro, que vai desde a pré-escola até o ensino superior.

Observa-se ao longo da história da humanidade, uma mudança na concepção da educação, visto que antes esta, a educação era limitada apenas ao período de crescimento e desenvolvimento da criança e hoje se estende pela vida toda. 
A Educação Especial apareceu pela primeira vez no contexto brasileiro através da Lei de Diretrizes e Bases da Educação (LDB), no 4.024 de 1961, em seu artigo 88, a qual aponta que "a educação dos excepcionais deve, no que for possível, enquadrar-se no sistema geral da educação, a fim de integrá-los na comunidade”, sendo esta lei revogada em dezembro de 1996.

Atualmente a Educação Especial está garantida pela Lei de Diretrizes e Bases para a Educação Nacional (LDB), no 9.394, de 20.12.1996. Introduzido neste contexto, o significado de educação constante na nova $\mathrm{LDB} / 96$, evidencia que ela:

\begin{abstract}
Abrange os processos formativos que se desenvolvem na vida familiar, na convivência humana, no trabalho, nas instituições de ensino e pesquisa, nos movimentos sociais e organizações da sociedade civil e nas manifestações culturais (BRASIL, 1996, p. 11).
\end{abstract}

Mas o que vem a ser Educação Especial? De acordo com o MEC (2002), essa modalidade de educação é considerada como um conjunto de recursos educacionais e de estratégias de apoio que estejam à disposição de todos os alunos, oferecendo alternativas de atendimento à pessoa com deficiência.

Para Freire e Scaglia (2003), na realidade, a Educação constitui um todo indissociável, não sendo possível formar personalidades autônomas no domínio moral se, por outro lado, o indivíduo for submetido a um constrangimento intelectual de tal ordem que tenha que limitar o aprender por imposição externa.

Para Sassaki (2004), decretos, leis, entre outros instrumentos formais, têm sido utilizadas, com frequência, pelo Estado em respostas as necessidades educacionais especiais dos indivíduos, o que vem a contribuir para na reflexão de valores e paradigmas estabelecidos em determinadas realidades, o que vem a ocasionar na mudança de mentalidade no processo histórico.

Para Silva (2002), as políticas voltadas à educação especial têm objetivos gerais e específicos voltados aos portadores de necessidades educacionais especiais, que procuram fundamentar e orientar o processo de educação especial, possibilitando garantir o atendimento educacional ao indivíduo portador de necessidades educacionais. Com isso, os objetivos apresentados por essa política de educação especial envolvem questões que abarcam atividades físicas, sociais, direitos de escolha, habilidades linguísticas, 
autonomia e qualificação profissional das pessoas portadoras de deficiência. Mas, para que essas questões se tornem uma prática social, é necessária maior oferta de serviços voltados à educação especial como equipamentos, mão de obra qualificada, material pedagógico especializado, espaço físico que atenda as peculiaridades de sua clientela e orientação aos familiares.

Segundo Motta (1997), a finalidade e os objetivos que a educação especial deve ter são a de identificar, assistir, reabilitar e integrar pessoas portadoras de necessidades especiais, por meio de uma ação democrática e da participação ativa da comunidade, das famílias e dos próprios benificiários, isto é, com base na comunidade que deve ser agente do processo de reabilitação e de inclusão social, através das ações preventivas das deficiências, buscando reduzir ou eliminar obstáculos do ambiente e do comportamento humano, utilizando soluções compatíveis e alternativas adaptadas para possibilitar a vida com exercício e cidadania em sua plenitude.

O Ministério da Educação/Secretaria de Educação Especial no ano de 2003 implantou o programa de Educação Inclusiva: direito à diversidade; contendo como objetivo alterar os sistemas de ensino para sistema educacional inclusivo.

É importante destacar que a educação, ao adotar a diretriz inclusiva no exercício de seu papel socializador e pedagógico, favorece a abertura solidária, sem preconceitos, de todos que são dignos e iguais na vida social.

\section{Princípios da educação inclusiva}

Para Sassaki (1997), a educação inclusiva consiste em uma metodologia de modificação cuja intenção é de transformar a visão educacional, não tendo em vista apenas alcançar o discente, mas a todos que fazem parte da educação. A inclusão social é o método pelo qual a sociedade e a pessoa portadora de deficiência buscam habituar-se reciprocamente, tendo em vista a equiparação de ensejos e, consequentemente, edificando uma sociedade para todos.

Sendo assim, a inclusão social, nada mais é do que um método que contribui para a formação de uma nova sociedade, por meio pequenas e grandes alterações, nos ambientes físicos (espaços externos e internos, meio de transporte, equipamentos, mobiliário, aparelhos e 
utensílios) e no entendimento de todas as pessoas, ou seja, da própria pessoa portadora de necessidades especiais (SASSAKI, 1997, p. 42).

Como pode ser visto, no Brasil, a educação especial é assunto novo, porém, a inclusão é um movimento histórico pelos direitos humanos, levando-se em consideração que tais princípios já vêm sendo vinculados em forma de declarações e diretrizes políticas.

Como nossa sociedade é exclusiva, isto é, as nossas escolas e nossa sociedade excluem aqueles que não estão dentro de determinados padrões e expectativas, concluise que a inclusão representa um desafio aos educadores, pois é preciso encontrar caminhos e meios para criar uma política de ação com recursos apropriados para todos os educandos.

Para Mantoan (2006), se a inclusão for uma das causas de fortes mudanças, há condições de se romper com certos paradigmas das instituições educacionais brasileiras e iniciar um processo gradual, mas firme, para redirecionar as práticas escolares e melhorar a qualidade de ensino a todos, pois muitas escolas já começaram a assegurar aos educando com deficiência o atendimento educacional especializado (AEE), feito em horário diferente ao da sala de aula regular na própria instituição em que o aluno frequenta, ou em outra próxima, em que lhe é oferecido recursos pedagógicos de acessibilidade, jogos pedagógicos, mobiliário adequado e equipamentos acessíveis que permitam a total participação e envolvimento do sujeito com deficiência de acordo com suas necessidades específicas em escolas inclusivas e por meio de salas de recursos multifuncionais.

Observa-se através disso um "processo de mudança, cujo movimento ruma para novas possibilidades para o ensino especial [...] em que a inclusão não pode ser mais ignorada”. Por isso a importância de reconhecer e valorizar as diferenças ainda mais no Brasil com suas diferenças culturais, étnicas, religiosas e regionais.

De acordo com Prieto (2006), um dos objetivos de processo de inclusão é reconhecer e valorizar a diversidade como condição do ser humano que favoreça o seu aprendizado. Com isso, as limitações dos alunos não devem ser ignoradas, mas algo a ser considerado durante a elaboração dos planejamentos de ensino em que o foco, diante dessa situação, deve recair sobre a identificação das suas possibilidades, favorecendo a 
construção de alternativas e condições e a autonomia escolar e social, para que todos se tornem cidadãos em igualdade e direitos.

Dessa forma, Glat e Nogueira (2002), afirmam que a inclusão de indivíduos com necessidades educacionais especiais na rede regular de ensino não consiste apenas na sua permanência junto aos demais alunos, nem na sua negação dos serviços àqueles que deles necessitem. Ao contrário, implica uma reorganização educacional, o que acarreta a revisão de antigas concepções e paradigmas educacionais na busca de se possibilitar o desenvolvimento cognitivo, cultural e social desses alunos, respeitando suas diferenças e atendendo às suas necessidades.

Destaca que para muitos casos de alunos com dificuldades de aprendizagem, mesmo não sendo alunos da educação especial, o que faz necessário, e é um direito que lhes assiste, é um atendimento pedagógico individualizado e um ensino de melhor qualidade na própria rede regular, para oferecer-lhes motivação adequada e condições de superação de seus problemas passageiros de desinteresse, de capacidade de memorização, de atenção, de compreensão, de participação e comportamento. Tais dificuldades são comuns em alunos de rede regular de ensino e é nela que devem ser encarados com profissionalismo e resolvidos, pois, se constituem nas principais causas de repetência e de evasão, de acordo com Motta (1997). A autora, justifica a criação de salas de apoio pedagógico específico nas escolas onde houver condições e necessidade, com base no princípio de que as diferenças individuais devem ser respeitadas e cada um tem direito de ter oportunidades iguais e não ser segregado, mesmo que, para garanti-lo seja necessário atendimento diferenciado e maior apoio familiar.

\section{A contribuição da família no desenvolvimento do aluno com deficiência intelectual}

O ambiente familiar é o primeiro local onde o aluno começa a estabelecer contatos sociais e futuramente adquirir autonomia, mas para que isso ocorra é necessário um ambiente receptivo e acolhedor para que isso se concretize de fato. Nesse sentido, família é vista como um núcleo social responsável pela transmissão de valores, costumes e ideias que estão presentes no cotidiano da sociedade. Ela tem uma grande influência no comportamento dos indivíduos, principalmente das crianças, que aprendem formas diferentes de ser, de ver o mundo e de interagir com ele, pois é através das interações familiares que se dão a transformações na sociedade e que também influenciarão todos 
os membros familiares e também os diferentes ambientes que compõem os sistemas sociais, dentre eles a escolas, e esta por sua vez, tem uma força propulsora no desenvolvimento da pessoa, segundo Zamberlan e Biasoli-Alves (1996),.

A família também é responsável pela transmissão de valores afetivos e culturais de uma geração para outra. Essa transmissão possibilita o compartilhar de regras, valores e perspectivas, valorizando o potencial de cada membro familiar a viver experiências diversificadas se integrando em grupos e vivendo todas as experiências possíveis.

De acordo com Marturano (1999), a família representa uma unidade dentro da sociedade, dentro dos limites impostos por essa sociedade, a criança se desenvolve aprendendo a ser o indivíduo esperado pela comunidade, definido como "normal". Todo envolvimento familiar durante o processo de desenvolvimento do aluno com deficiência intelectual vai incluir não apenas doses de atenção, mas também uma postura centralizada no aluno. É com esse envolvimento que a família irá proporcionar recursos emocionais essenciais para o desenvolvimento de um verdadeiro senso de competência, para mais tarde fornecer recursos mais concretos como assistência nas lições de casa, o que permitirá um melhor desempenho na escola.

De acordo com Rey e Martinez (1989), Silva e Dessen (2001), a influência da família se dá primeiramente, no desenvolvimento do aluno, através das relações por meio de um elemento fundamental: a comunicação, tanto verbal quanto a não verbal. Desta forma, a família representa talvez, a forma de relação mais complexa e de ação mais profunda sobre a personalidade humana, dada enorme carga emocional das relações entre seus membros, assim diversas interações e relações desenvolvidas entre os elementos familiares demonstram que o desenvolvimento do sujeito não deve ser isolado do desenvolvimento familiar.

Esses fatores irão facilitar o processo de estímulo, de contato e interação social, pois quando há um ambiente familiar acolhedor e compreensivo, esse respeito acaba se estendendo para as relações externas o que contribui realmente para o desenvolvimento psicossocial e as relações humanas.

\section{CONCEITO DE SOFTWARE EDUCATIVO}

A utilização da informática na educação vem ganhando, nas últimas décadas, um espaço significativo na área da informática, pois os computadores estão cada vez mais 
presentes no dia a dia da sociedade, fazendo-se necessário uma reflexão sobre como utilizar essa ferramenta tecnológica como recurso didático na metodologia de ensinoaprendizagem através da utilização de softwares educativos.

Com a ajuda do software, o educando consegue adquirir conhecimentos sobre vários conceitos, possibilitando a ele uma melhor compreensão da vida real.

Não existe um momento próprio para o educando desenvolver inteligência e nem outro do educando já estar inteligente, pois é sempre possível progredir e se aperfeiçoar. Uma utilização básica de muita importância é a possibilidade da construção da autoconfiança (RIZZO, 1988, p. 69).

Os softwares educativos devem ser entendidos como um programa idealizado com o objetivo oferecer aos seus usuários algum tipo de ensinamento, encontrando-se associado ao âmbito da educação formal, no entanto podem também existir outras variedades de programas indicados para a educação informal.

O software educativo é denominado como um conjunto de métodos informáticos elaborados com a finalidade de serem utilizados em ambiente escolar para a contribuição da aprendizagem (SANCHO, 1988, p. 69).

Pode-se dizer que o software educativo é uma derivação explícita da importância desenvolvida pela informática com o decorrer do tempo. Sem dúvida, compreende uma enorme chance de evolução para o educando, pois essa ferramenta tem se apresentado progressivamente eficaz.

Para Meirelles (1988) software é a expressão universalmente seguida para indicar as linguagens a serem interpretadas pelo computador, é um sequencial de instruções a serem seguidos para que ele processe as informações promovendo a interação entre usuário e computador.

É denominado software educativo àqueles programas que têm entendimentos educativos e pedagógicos, ou seja, as aplicações que 
buscam apoiar direta ou indiretamente os procedimentos de ensino e aprendizagem (MEIRELLES, 1988, p. 51).

De acordo com Pressman (2010) software tem o seguinte conceito:

- 1 - Códigos (Instruções do computador) que, quando executado, produz a função e o desempenho desejado;

- 2 - Estrutura de dados que possibilita que o programa manipule corretamente a informação;

- 3 - Documentos que descrevem a utilização e a operação dos programas.

Os softwares educativos propostos à educação são recomendados e definidos por faixa etária, conforme o conteúdo trabalhado em sala de aula. Conforme o Estatuto da Criança e do Adolescente (ECA) no seu art. 20 da Lei no 8.069, de 13 de julho de 1990 é considerado criança pessoas com até doze anos incompletos, adolescente pessoas entre doze e dezoito anos de idade.

Segundo Valente (1997) é importante que se utilize de maneira inteligente o computador aliado ao software educativo, dando prioridade para a parte pedagógica e não apenas a apresentação visual. A uso desta tecnologia serve para que o educando absorva um novo jeito conteúdos abordados em classe.

Entende - se que o software educativo é um método que deve estar integrado ao projeto educacional da escola como um dos recursos instrutivos disponibilizados para o educador na sua função de mediador do procedimento de ensino aprendizagem (OLIVEIRA, 2011, p. 90).

De acordo com Barros (2012) tem que ser observados alguns assuntos primordiais referentes ao processo de aquisição de conhecimento para que seja escolhido um software educativo de qualidade, de forma consciente, como as etapas de amadurecimento do cognitivo, o desenvolvimento do ser racional e a evolução particular que cada idade passa.

\section{Tipos e classificações de softwares no ambiente educativo}


Para Valente (1999), a classificação dos softwares educativos pode ser feita conforme a manipulação do conhecimento, podendo caracterizar sua modalidade como uma versão computadorizada da metodologia tradicional da educação escolar.

A Informática na educação tem diversas hipóteses baseadas na visão dos educadores e das condições pedagógicas em que o computador é utilizado. De acordo com alguns pesquisadores, a informática na educação significa a introdução do computador no desenvolvimento do ensino-aprendizagem, do conteúdo curricular de todas as modalidades e níveis de educação.

O software educativo pode ser um objeto de aprendizagem que tem uma reutilização bastante facilitada, tendo duas vertentes principais, as instrucionista e a construcionista.

Essa questão trata da fundamental importância da informática na composição de conhecimento em diferentes metodologias e também faz com que o educador também tenha uma prática habitual de ser um fomentador de novas formas de trabalho que envolva o computador, pois as atividades de uso do computador podem ser feitas tanto para continuar passando a informação para o educando, deste modo reforçando o processo instrucionista, quanto para elaborar condições para o educando desenvolver seu conhecimento através da criação de ambiente de aprendizagem que utilizem o computador.

Esse paradigma do instrucionismo consiste em executar no computador uma quantidade de informações e essas informações são transmitidas ao educando na forma de um jogo, tutorial, exercício-e-prática, simulação. $O$ paradigma transfere para o computador a função de ensinar, reforçando as atividades que foram realizadas na sala de aula. O método de ensino ainda mais utilizado nas escolas é o instrucionista.

Os softwares instrucionistas, são softwares que normalmente trabalham com interações pobres, como a simples apresentação de conteúdo ou em questões diretas sobre uma determinada matéria. A máquina instrucional, é como se fosse um professor onde o educando precisará responder apenas o que computador lhe pergunta, o educando não necessita pensar, o programa dá instruções de comando (CHAVES, 1983, p. 89). 
O Construcionismo pode ser compreendido como uma teoria que tem a finalidade de estudar o desenvolvimento e a utilização da tecnologia, do computador em especial, na criação de ambientes educacionais.

De acordo com Papert (1986) a abordagem construcionista é a forma pela qual o educando constrói o seu próprio conhecimento por intermédio do computador, passando o computador a ser apenas um apoio, em que o educando ensina o computador por meio da interação, exploração, descoberta e investigação. No construcionista o educando cria algo de seu interesse, o que torna a aprendizagem mais prazerosa.

Um ponto muito importante do Construcionismo é que ele vai além do ponto de vista cognitivo, incluindo também as especificidades sociais e afetivas da educação. Abrindo assim em espaço para os estudos das questões da tecnologia, cultura, gênero, motivação, personalidade, etc. que geralmente não são comentados nos assuntos educacionais mais tradicionais.

Construcionismo é um resumo da teoria de Piaget e da oportunidade oferecida pela informática para o desenvolvimento de uma educação contextualizada, onde os alunos trabalhem na criação de elementos significativos e por meio da qual determinada percepção e acontecimentos possam ser compreendidos e aplicados (PAPERT, 1986, p. 8).

Para Chaves (1983), os softwares construcionistas levam o educando a criar, explorar, inovar, buscar soluções para os desafios propostos, passando a ser um participante ativo no processo de construção da sua própria atividade, assim, o discente pode errar e acertar seus erros, além de poder criar e recriar suas próprias atividades.

O interessante dessa abordagem é notar que, neste procedimento da construção, o usuário não passa diretamente de um nível de conhecimento para outro mais avançado, o aprendizado se dá por meio da construção de uma sequência de conceitos transitórios.

Esse método ocorre mediante as tentativas e erros, no qual o usuário parte das vertentes já conhecidas do problema e segue desenvolvendo suas próprias teorias, sendo que as teorias que não forem compatíveis vão sendo alteradas ou descartadas até se tornarem gradualmente mais estáveis. 
Sob este aspecto, os erros são tão importantes quanto os acertos para o desenvolvimento do ensino-aprendizagem. À medida que os acertos constituem as situações relativas à adequação do conhecimento do usuário com relação às coisas da vida real, são os "erros" que contrariam esta estabilidade e funcionam como a força motora no processo de ensino-aprendizagem.

Segundo Valente (1999) os softwares instrucionistas e construcionistas podem ser divididos em:

Jogos Educacionais: Em regra não há necessidade de uma instrução detalhada do que está sendo sugerido na atividade, permitindo ao educando sentir-se o criador efetivo do seu próprio conhecimento. Os jogos educacionais são constituídos de várias fases a serem atingidas e, e ao concluírem esta, passam para uma nova fase, que tem o grau de dificuldade aumentado modificando a maneira de resolver os problemas apresentados. Há uma grande perda da proposta pedagógica neste tipo de software, pois os educandos objetivam apenas concluir todas as fases, focando, assim, apenas no lazer momentâneo e não no aprendizado, conforme mostra a figura 1.

Figura 1 - Jogo das Sombras da Mônica

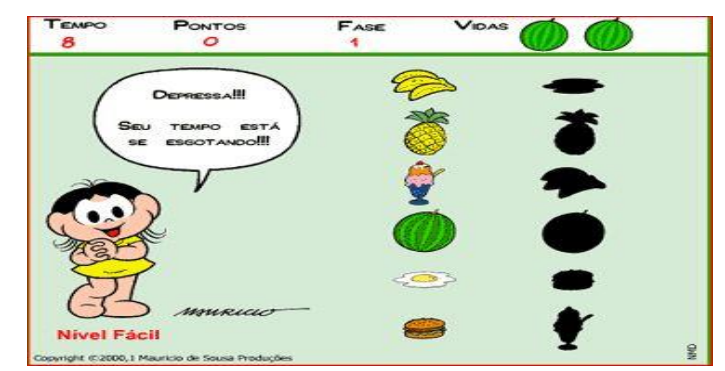

Fonte: Patrícia Mendonça (2007)

Tutoriais: A instrução é dada de maneira bem simples e quando o educando comete algum erro é detectado e mostrado na tela. $\mathrm{O}$ educando pode errar várias vezes, pois como o "professor" é a máquina virtual, a mesma ficará apontando incansavelmente o mesmo erro toda vez que ele acontecer. Este software não é acatado como um software inovador, pois tem como base a projeção de um texto e pergunta a ser respondida, que em regra são de múltipla escolha. A figura 3 mostra um exemplo de software tutorial. 
Figura 1 - A água - Recreio on-line

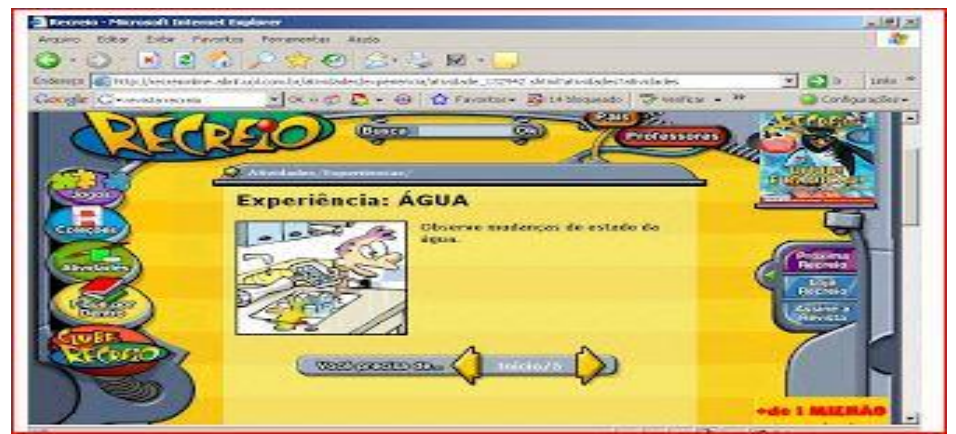

Fonte: Patrícia Mendonça (2007)

Simulação: Caracteriza-se pelos gráficos atraentes e pela semelhança que cria do educando com os difíceis casos que ocorrerem na vida real. Para o educando alcançar determinada fase do programa é necessário tomar algumas decisões, por isso é muito importante que o educador esteja sempre presente, para que o educando não tenha uma visão distorcida da vida real, pois um simples comando seu é o suficiente para que situações possam ser controladas ou modificadas, conforme mostra a figura 3.

Figura 3 - Aquecimento do Planeta - Turma do Super V

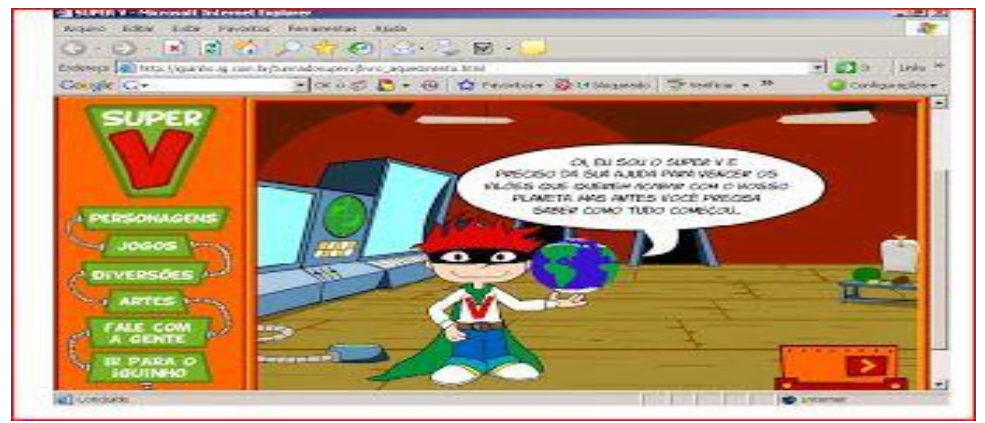

Fonte: Patrícia Mendonça (2007)

Exercício e prática: permite uma maior interatividade do educando com a máquina, apontando o erro quando cometido, é um grande aliado para reforçar os assuntos já abordados em sala de aula, por meio de exercícios de memorização e repetição. 
É um grande aliado para alguns educadores, pois pode detectar quais educandos estão com mais problemas de aprendizagem a partir da quantidade de erros cometidos no desenvolvimento da atividade. A figura 4 mostra o exemplo de como funciona este tipo de software.

Figura 4 - Jogo da Matemática - Recreio On-line

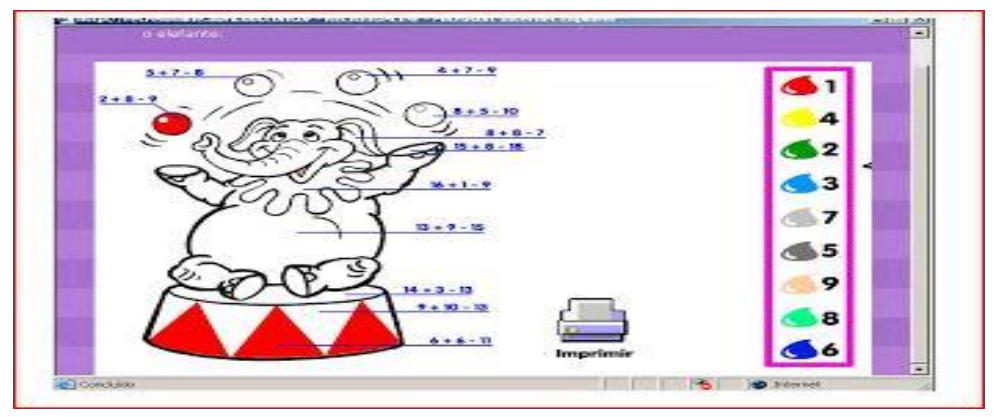

Fonte: Patrícia Mendonça (2007)

\section{Pesquisa de softwares educativos livres, interfaces e interatividade}

De acordo com Melo e Antunes (2002), o software livre educacional, oferece grande proveito no que diz respeito a custo-benefício, pois mesmo que alguns programas possam ser comercializados, na maioria das vezes são gratuitos proporcionando assim a opção de serem baixados pela internet.

Outro fator importante é em relação à liberdade que se tem para fazer alteração no código-fonte, podendo assim essa ferramenta ser adaptada para ser usada mais efetivamente para a finalidade na qual foi projetado. E como são desenvolvidos sem o objetivo de retorno financeiro, estes tipos de software acabam abrangendo mais as necessidades educacionais.

Abaixo, foram relacionados alguns tipos de softwares educativos utilizados na educação especial:

Cobpaint - O software contém uma interface bastante atrativa, sendo também um programa de desenho muito utilizado na educação especial com crianças que não conseguem utilizar o paint ou outros softwares de desenho. Na figura 5 abaixo, mostra o exemplo deste tipo de software. 
Figura 5 - Software Cobpaint

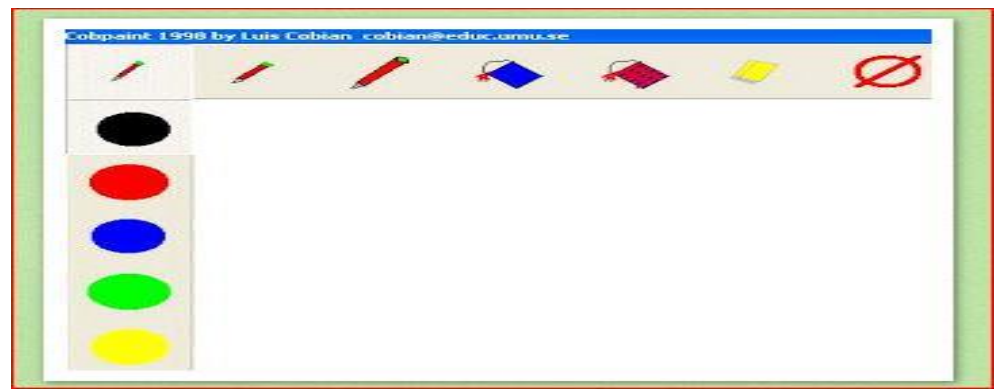

Fonte: Catarina Couto (2011)

Tux Paint: É um software free com uma interface muito simples e intuitiva. Possui diversas ferramentas de pintura e desenho e tem como objetivo despertar a criatividade do educando, conforme mostra a figura 6.

Figura 6 - Software Tux Paint

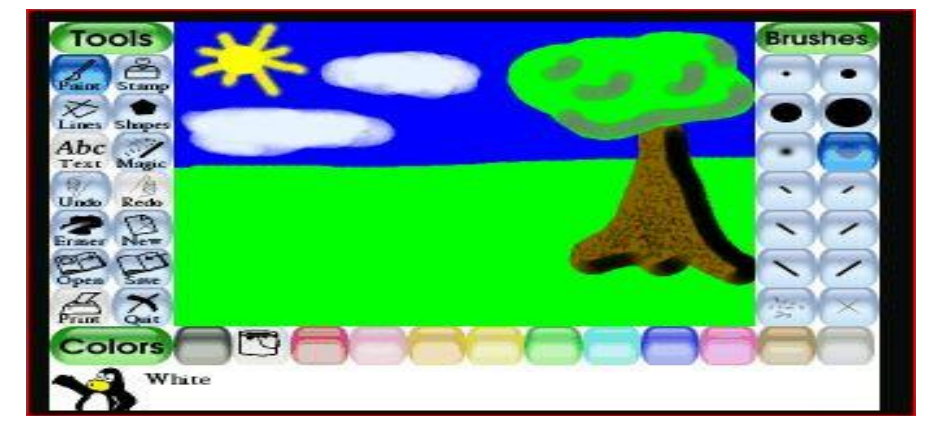

Fonte: Catarina Couto (2011)

Imagina - Este software possui uma interface de manipulação direta e alargada, uma hierarquia de processos independentes e paralelos, objetos e comportamentos, ferramentas de desenho e animação. Foi elaborado para professores, estudantes e programadores permitindo: desenvolver aplicações para internet, criar desenhos e animações, utilizar sintetizador de voz, criar aplicações multimídia em formato exe. construir ambientes de aprendizagem, compor e explorar peças musicais, comunicar ideias e construir apresentações. A figura 7 mostra o exemplo deste tipo de software. 
Figura 7 - Software Imagina

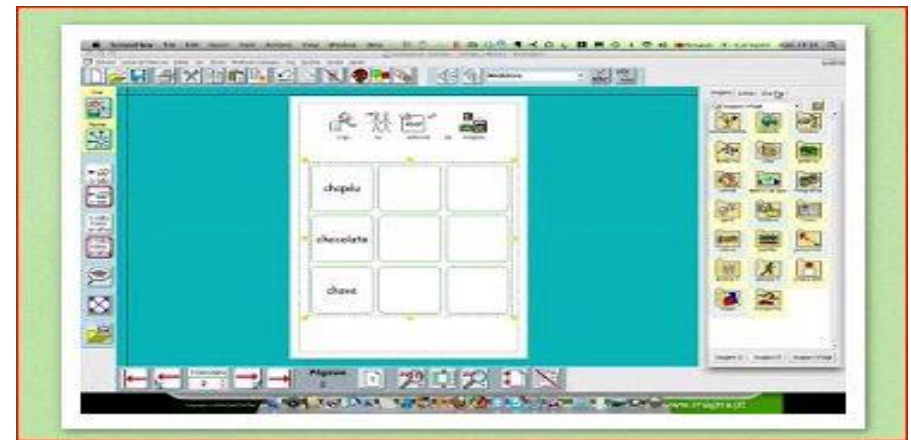

Fonte: Catarina Couto (2011)

É muito importante que o software educativo tenha uma interface agradável, pois resulta em um desempenho positivo.

Quanto mais fácil for o manuseio do software, os educandos terão mais interesse em descobrir o diferencial que software pode lhe oferecer. Se o software tiver uma interface difícil de ser entendida, com muitas informações desnecessárias e com muitos erros, tira a motivação do educando em manusear o programa além de debilitar o seu rendimento.

Segundo Santos (2001), a interface tem que ser amigável, dando prioridade para a usabilidade para que o educando consiga entendê-la e fazer desta ferramenta um apoio para processo pessoal de conhecimento

[...] é muito importante que seja mantido um padrão na interface de um mesmo software educativo, com menus facilitadores de localização, cores agradáveis, animações pertinentes e que ajudem o educando na interatividade e na exploração do software (SANTOS, 2001 p. 35).

Ainda segundo Santos (2001), existem no mercado vários tipos de interfaces, sendo que os principais tipos de interfaces e suas respectivas características são:

Interfaces para Web: Não existe muita diferença entre os sites educativos que estão disponíveis na web dos destinados para outras finalidades, porém, sites de jogos que permitem uma maior interatividade e o emprego de realidade virtual em 
determinadas páginas acrescem novas apreciações para esse tipo de interface. A figura 8 mostra um exemplo de interface gráfica.

Figura 8 - Interface Gráfica Principal Kit interface do jogo menu

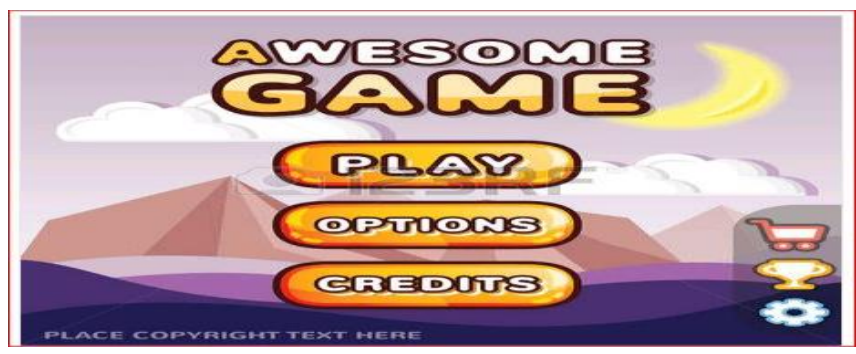

Fonte: Yulia Kireeva - Russian Federation (2017)

Interfaces Hipermídia: As informações são interligadas por meio de animações, imagens, sons diferenciados, textos, vídeos e músicas, conforme pode-se observar no exemplo da figura 9.

Figura 9 - Interface de Multimídia - ViewPro

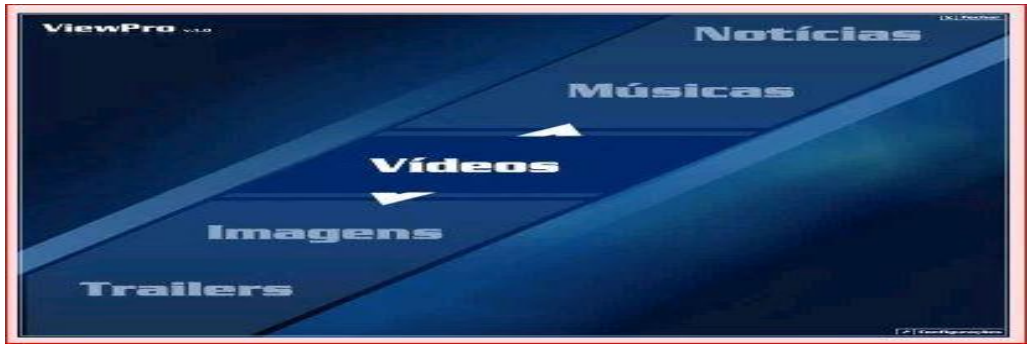

Fonte: Grupo: Celso Rorato / Rodrigo Ginevro - DMD 4-A (2007)

Interfaces Adaptativas: Auxiliam o usuário nas buscas feitas na web, devem ser mais complacentes a erros e apresentar formatos agradáveis, fazendo com que a interação com o usuário seja mais natural. A figura 10 mostra um exemplo de interface adaptativa.

Figura 10 - Interface-do-usuario-UI_thumb 


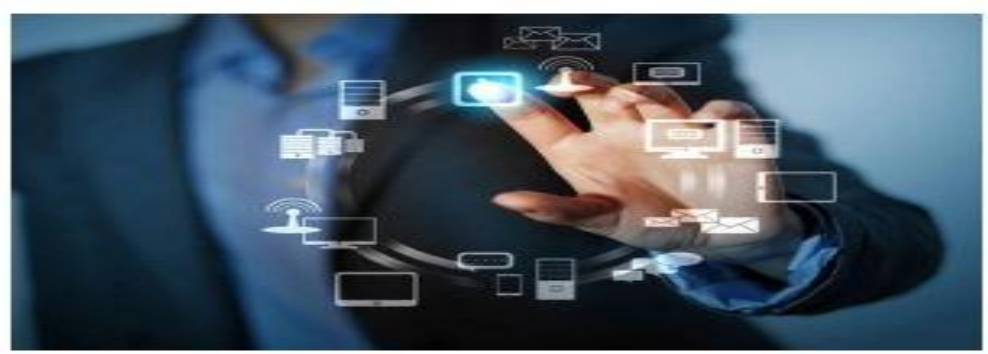

Fonte: interfacesadaptativas (2015)

É muito importante que os softwares, de modo geral, tenham uma interface que seja agradável, priorizando a facilidade de uso de programa e a obtenção dos objetivos do usuário. Mesmo possuindo uma visão comercial, os desenvolvedores mostram que mesmo com um software simples de se manusear e com informações importantes disponíveis na tela, os usuários melhoram muito o seu desempenho.

Isso é de extrema importância em softwares educativos, pois, quanto mais fácil for seu manuseio, os educandos terão mais interesse em descobrir o diferencial que o software pode lhe oferecer.

\section{Considerações Finais}

Um ambiente pedagógico, quando informatizado, propicia que o educando com deficiência intelectual tenha um melhor desenvolvimento cognitivo se houver o intermédio de um (a) educador (a) especialista, com o objetivo de alcançar o desenvolvimento pleno dessa pessoa como um ser social e histórico, olhando para essa pessoa não com um ser limitado e inferior, mas como uma pessoa que aprende de forma diferente dos padrões e das normas especificadas pela sociedade dos ditos "normais".

A produção de softwares educativos impulsionou fortemente essa nova realidade e a sua inserção nas práticas pedagógicas.

Os softwares educativos se apresentam em diferentes tipos como os de exercício e prática, tutoriais, simulação e jogos, mas independentemente do tipo, estes softwares estimulam o educando a ter uma melhor interação com o computador permitindo a ele, o desenvolvimento de suas habilidades motoras, através do teclado e do mouse. 
Acredita-se que, com as interações que o educando com deficiência intelectual estabelece na relação educando/educador/computador em diferentes situações, podem propiciar grande experiência de aprendizagem não restrita apenas aos fundamentos do currículo costumeiro.

O software educativo é muito complexo para ser desenvolvido, principalmente no que diz respeito aos conceitos de interdisciplinaridade presente, e mais ainda para o público qual está sendo desenvolvido, pois há a necessidade de levantamento de requisitos mais específicos.

Além do mais, ela facilita para os educadores uma melhor visualização e entendimento, visto que os mesmos permanecem em contato direto com o software, aumentado assim, as participações e as contribuições pedagógicas.

Conclui-se que os aplicativos são muito importantes, pois, por intermédio destas ricas considerações e explosões de ideias são dogmaticamente observados na avaliação de desempenho dos educandos, haja vista que a inovação e diversidade ainda são consideradas como fortes atrativos para a aprendizagem de modo geral

\section{Referências}

A.A.M.R. Retardo Mental: definição, classificação e sistema de apoio. 10. ed. Porto Alegre: Artmed, 2006.

ARAUJO, L. A. de; CORDEIRO, A. P.; GIROTO, C. R. M. Um encontro com a diversidade na educação infantil por meio do projeto "simplesmente diferente" sob a perspectiva do professor, da criança e da família. Revista Ibero-Americana de Estudos em Educação, [S.1.], p. 775-790, may 2019. ISSN 1982-5587. Disponível em: $<$ https://periodicos.fclar.unesp.br/iberoamericana/article/view/12206>. Acesso em: 27 june 2019. doi:https://doi.org/10.21723/riaee.v14iesp.1.12206.

Associação Americana sobre Deficiência Intelectual do Desenvolvimento - AAIDD. Definição de Deficiência Intelectual. Disponível em: <https://aaidd.org/intellectualdisability/definition\#.WaNS1viGNdg>. Acesso em 07 mar. 2019.

BRASIL. Constituição da República Federativa do Brasil de 1988. Disponível em: <https://www.planalto.gov.br/ccivil_03/constituicao/constituicao.htm>. Acesso em 13 mar. 2019. 
BRASIL. Estatuto da Criança e do Adolescente. Lei Federal no 8.069, de 13 de junho de 1990. Disponível em: <https://www.planalto.gov.br/ccivil_03/leis/L8069.htm>. Acesso em 20 mar. 2019.

BRASIL. Declaração de Salamanca: Sobre Princípios, Políticas e Práticas na Área das Necessidades Educativas Especiais. 1994. Portal MEC. Disponível em: <http://portal.mec.gov.br/seesp/arquivos/pdf/salamanca.pdf> Acesso em: 20 mar. 2019.

BRASIL. Lei de Diretrizes e Bases da Educação Nacional (LDB), no 9.394, de 20 de dezembro de 1996. Disponível em:

<https://www.planalto.gov.br/ccivil_03/Leis/L9394.htm>. Acesso em 13 mar. de 2019.

BRASIL. Decreto No 5.296, de 02 de dezembro de 2004. Disponível em: <http:/www.mc.gov.br/legislacao/por-tipo/decretos/decreto-n-5-296-de-2-de dezembro-de-2004>. Acesso em: 20 mar. 2019.

BRASIL. Institui a Lei Brasileira de Inclusão da Pessoa com Deficiência (Estatuto da Pessoa com Deficiência). Lei no 13.146, de 6 de julho de 2015. Disponível em: <http://www.planalto.gov.br/ccivil_03/_ato2015-2018/2015/lei/113146.htm>. Acesso em: 14 de mar. 2019.

BRASIL. Convenção Sobre os Direitos das Pessoas com Deficiência. Disponível em: <http://www.planalto.gov.br/ccivil_03/_ato2007-2010/2009/decreto/d6949.htm>. Acesso em 13 mar. 2019.

BRASIL. Ministério da Educação. Secretaria de Educação Continuada, Alfabetização, Diversidade e Inclusão. Legislação. Disponível em:

$<$ http://portal.mec.gov.br/secretaria-de-educacao-continuada-alfabetizacao-diversidadee-inclusao/legislacao>. Acesso em 13 mar. 2019.

BRUNO, M. M. G.; NOZU, W. C. Shoiti. Política de inclusão na educação infantil: avanços, limites e desafios. Revista Ibero-Americana de Estudos em Educação, [S.1.], p. 687-701, may 2019. ISSN 1982-5587. Disponível em:

<https://periodicos.fclar.unesp.br/iberoamericana/article/view/12199>. Acesso em: 27 june 2019. doi:https://doi.org/10.21723/riaee.v14iesp.1.12199. 
CARDOZO, A. S. M. S. A atuação do psicopedagogo na escola inclusiva. Revista AVM, Niterói RJ, 2011. Disponível em:

<http://www.avm.edu.br/docpdf/monografias_publicadas/N204418.pdf >. Acesso em 20 mar. 2019.

CHAVES, E. O. C. Multimídia: Conceituação, Aplicações e Tecnologia. Campinas: People Computação Editora, 1983.

COUTO, C. Materiais de Apoio à Educação Especial. Portugal, 09 jul. 2011.

Disponível em: <http://comunicarsemfronteiras.blogspot.com.br/>. Acesso em 06 maio. 2019.

DÉA, V. H. S. D.; DUARTE, E. Síndrome de Down: informações, caminhos e histórias de amor. 1 ed. São Paulo: Phorte, 2009.

DOUGLAS J. Tópicos Projetos. Design de interface para ambiente de pesquisa Cultural Analytics. 07 de mai. 2008. Disponível em: <http://lab.softwarestudies.com/2008/05/surface-is-new-depth-multiple.html\#links>. Acesso em 07 maio 2019.

FREIRE, J. B.; SCAGLIA, A. J. Educação como prática corporal. 1ª Ed. São Paulo: Spicione, 2003.

GIROTO, C. R. M.; ARAUJO, L. A. de; VITTA, F. C. F. de. Discursivização sobre "doenças do não aprender" no contexto educacional inclusivo: o que dizem os professores de educação infantil?. Revista Ibero-Americana de Estudos em Educação, [S.1.], p. 807-825, may 2019. ISSN 1982-5587. Disponível em: <https://periodicos.fclar.unesp.br/iberoamericana/article/view/12208>. Acesso em: 27 june 2019. doi:https://doi.org/10.21723/riaee.v14iesp.1.12208.

GIROTO, C. R. M.; VITTA, F. C. F. de; ARAUJO, L. A. de. Inclusão e educação infantil. Revista Ibero-Americana de Estudos em Educação, [S.1.], p. 635-640, may 2019. ISSN 1982-5587. Disponível em:

<https://periodicos.fclar.unesp.br/iberoamericana/article/view/12214>. Acesso em: 27 june 2019. doi:https://doi.org/10.21723/riaee.v14iesp.1.12214. 
GLAT, R.; NOGUEIRA, M. L. de L. Políticas educacionais e a formação de professores para a educação inclusiva no Brasil. Revista Integração. Brasília: ministério da Educação, ano 14, no 24, 2002.

GONÇALVES, F. Do andar ao caminhar: um caminho psicomotor. 1 ed. São Paulo: Cultural RBL, 2009.

INTERFACESADAPTATIVAS. Interface Adaptativas. 01 jun. 2015. Disponível em: <https://interfacesadaptativas.wordpress.com/author/interfacesadaptativas/>. Acesso em 30 abr. 2019.

KENSKI, V. M. Educação e tecnologias: o novo ritmo da informação. Brasília: Papírus. 2007.

LEFRANÇÓIS, G. R. Teorias da aprendizagem. 5 ed. São Paulo: Cengage Learning, 2008.

MANTOAN, M. T. E. Compreendendo a deficiência mental. 1 ed. Campinas: Ed. Scipione, 2001.

MATOAN, M. T. E. Igualdade e diferenças na escola: como andar no fio da navalha. In: ARANTES, V. A. (Org). Inclusão escolar. São Paulo: Simmus, p. 15-30, 2006.

MANTOAN, M. T. E.; BATISTA, C. A. M. Atendimento Educacional Especializado em Deficiência Mental. In: GOMES, Adriana L. Limaverde Gomes... [et al.] Deficiência Mental. São Paulo: MEC/SEESP, 2007. (Série Atendimento educacional especializado). Disponível em: <http://portal.mec.gov.br/seesp/arquivos/pdf/aee_dm.pdf〉. Acesso em 18 mar. 2019.

MARCONI, M. A; LAKATOS, E.M. Fundamentos de metodologia científica. 7 ed. São Paulo: Atlas, 2010.

MATURANO, E. M. Ambiente familiar e aprendizagem escolar. Revista Psicopedagogia, v. 18, no 47, p. 21-25. 1999.

MAZZOTTA, M. J. S. Fundamentos de Educação. Série Cadernos de Educação Biblioteca Pioneira de Ciências Sociais. São Paulo: Guazzelli \& Cia Ltda, 1987. 
MEIRELLES, F. S. Informática: novas aplicações com microcomputadores. São Paulo: McGraw-Hill. 1988.

MENDONÇA P. Tipos de Softrware Educativo. Porto Alegre 30 out. 2007. Disponível em: <http://sweducativo.blogspot.com.br/>. Acesso em 06 maio. 2019.

MONTEIRO, S. A. de S.; RIBEIRO, P. R. M. O lugar das crianças com deficiências na educação infantil e políticas de inclusão na educação brasileira. Revista IberoAmericana de Estudos em Educação, [S.1.], p. 730-745, may 2019. ISSN 1982-5587. Disponível em: <https://periodicos.fclar.unesp.br/iberoamericana/article/view/12203>. Acesso em: 27 june 2019. doi:https://doi.org/10.21723/riaee.v14iesp.1.12203.

MOTTA, E. O. Direito Educacional e educação no século XXI. Brasília: UNESCO. 1997.

OFICINA DA NET. Quais são os Softwares Livres mais utilizados? 02 abr. 2014. Disponível em: <www.oficinadanet.com.br/post/11012-quais-sao-os-softwares-livres mais-utilizados>. Acesso em 05 maio. 2019.

OMOTE, S. Deficiência e Não-Deficiência: Recortes do mesmo tecido. Cadernos de Educação Especial, Santa Maria: n. 2, p. 65-73, 1994.

PAPERT, S. A máquina das crianças: repensando a escola na era da informática. Trad. Sandra Costa. Ed. revisada. Porto Alegre: Artmed, 1986.

PIETRO, R. G. Atendimento escolar de alunos com necessidades educacionais especiais: um olhar sobre as políticas públicas e educação no Brasil. In: ARANTES, V. A. (Org). Inclusão escolar. São Paulo: Simmus, p. 31-73, 2006.

REY, F. G.; MARTINEZ, A. M. La personalidad: sua educación y desarrollo. La Habana: Editorial Pueblo y Educación, 1989.

RODRIGUES, C. Forma criativas para estimular a mente de alunos com deficiência. Revista nova escola. Edição 223, jun. 2009. Disponível em: $<$ http://novaescola.org.br/formacao/formas-criativas-estimular-mente-deficientesintelectuais-476406.shtml>. Acesso em: 13 mar. 2019. 
SALTO, M. P; CARNEIRO, R. U. C. A concepção docente em uma experiência de educação infantil inclusiva: um estudo de caso. Revista Ibero-Americana de Estudos em Educação, [S.1.], p. 855-868, may 2019. ISSN 1982-5587. Disponível em: $<$ https://periodicos.fclar.unesp.br/iberoamericana/article/view/12211>. Acesso em: 27 june 2019. doi:https://doi.org/10.21723/riaee.v14iesp.1.12211.

SANCHO, J. M. Tecnologias para transformar a educação. Porto alegre: Artmed, 1988.

SANTAROSA, L. C. et al. Ambiente de aprendizagem computacionais como "prótese" para o desenvolvimento de jovens portadores de paralisia cerebral. Integração, Brasilia, n. $17,1996$.

SASSAKI, R. K. Inclusão: construindo uma sociedade para todos. 3. ed. Rio de Janeiro: WVA, 1997.

SASSAKI, R. K. Pessoas com deficiência e os desafios da inclusão. Revista Nacional de Reabilitação, jul./ago., 2004.

SILVA, L. C. da; SILVA, F. D. A.; FALEIRO, W. Educação infantil e educação especial: entre as fronteiras do favor e do direito de todos às condições de cidadania. Revista Ibero-Americana de Estudos em Educação, [S.1.], p. 702-716, may 2019. ISSN 1982-5587. Disponível em:

$<$ https://periodicos.fclar.unesp.br/iberoamericana/article/view/12200>. Acesso em: 27 june 2019. doi:https://doi.org/10.21723/riaee.v14iesp.1.12200.

SILVA, N. L. P.; DESSEN, M. A. Deficiência mental e família: implicações para o desenvolvimento da criança. Psicologia: teoria e pesquisa, v. 17, no 2, maio/ago., p. 133$141,2001$.

SILVA, R. N. A. A educação especial de criança com Síndrome de Down. 140 f. Monografia (Licenciatura em Biologia). Universidade Viega de Almeida, Rio de Janeiro. 2002.

SIPES, M. Inclusión en educación: perspectivas que rozan lo político y cincelan lo humano. Revista Ibero-Americana de Estudos em Educação, [S.1.], p. 717-729, may 
2019. ISSN 1982-5587. Disponível em:

<https://periodicos.fclar.unesp.br/iberoamericana/article/view/12202>. Acesso em: 27 june 2019. doi:https://doi.org/10.21723/riaee.v14iesp.1.12202.

TECNOBLOG. Software. Interface Customizável. 2014. Disponível em: <https://tecnoblog.net/153645/beta-firefox-29-interface-nova-mais-customizavel/>. Acesso em 05 maio. 2019.

TechTudo. O que é Realidade Virtual?. 09 set. 2015. Disponível em: <http://www.techtudo.com.br/noticias/noticia/2015/09/o-que-e-realidade-virtualentenda-melhor-como-funciona-a-tecnologia.html>. Acesso em 06 maio. 2019.

VALENTE, J. A. Análise dos diferentes tipos de softwares usados na educação. 1997. Disponível em: <http://pt.slideshare.net/anapierina/analise-dos-diferentes-tipos-desoftware>. Acesso em 19 mar. 2019.

WERNECK, C. Ninguém vai ser bonzinho na sociedade para todos. Rio de Janeiro: WVA, 1997.

WERNER, H. M. L. O processo da construção do número, o lúdico e TICs como recursos metodológicos para a criança com deficiência intelectual. Secretaria do Estado de Educação Superintendência da Educação Diretoria de Políticas e Programas Educacionais Programa de Desenvolvimento Educacional - PDE. Paranaguá- PR. 2008.

ZAMBERLAN, M. A. T.; BIASOLI-ALVES, M. M. Interações familiares: teoria, pesquisa e subsídios à intervenção. Londrina: Editora da UEL, 1996. 